Revista Brasileira de Agricultura Irrigada v.14, nº.2, p. 3906 - 3918, 2020

ISSN 1982-7679 (On-line)

Fortaleza, CE, INOVAGRI - http://www.inovagri.org.br

DOI: $10.7127 /$ rbai.v14n101096

Protocolo 1096.20 - 14/06/2019 Aprovado em 12/06/2020

\title{
NÍVEIS DE IRRIGAÇÃ̃ ASSOCIADOS A DOSES DE HIDROGEL NA CULTURA DO PIMENTÃO
}

\author{
Hélio Aparecido de Matos Filho ${ }^{1}$, César Antônio da Silva², Alefe Viana Souza Bastos ${ }^{3}$
}

\begin{abstract}
RESUMO
Objetivou-se, através deste trabalho, avaliar o desenvolvimento e produção de plantas de pimentão, cultivar Nathalie, em função de níveis de irrigação e doses de hidrogel. O experimento foi conduzido em um Latossolo Vermelho Amarelo, no Instituto Federal Goiano, em Morrinhos, Goiás. O delineamento foi o de blocos ao acaso, com quatro repetições, no esquema de parcelas subdivididas $4 \times 5$, sendo quatro níveis de irrigação (reposição de $50 \%, 75 \%, 100 \%$ e $125 \%$ da evaporação em tanque classe A- ECA) e cinco doses de hidrogel $\left(0,125,250,375\right.$ e $\left.500 \mathrm{~mL} \mathrm{cova}^{-1}\right)$. O hidrogel foi diluído em água a 2,5 $\mathrm{g} \mathrm{L}^{-1}$, sendo fornecido na cova de transplantio. Foram avaliados os seguintes parâmetros: altura de planta e diâmetro de caule, aos 90 e 120 dias após transplantio (DAT); número de frutos por planta, diâmetro do fruto, $\mathrm{pH}$ do fruto, produção de frutos comerciais, aos 100 e 120 DAT; e eficiência no uso da água (EUA). O excesso de irrigação, em nível maior ou igual a 100\% da ECA, ocasionou redução do número de frutos comerciais, da produção de frutos por planta, do diâmetro e pH do fruto. A adição de hidrogel no solo não propicia aumento significativo na produção e qualidade dos frutos. A irrigação a 75\% da ECA propiciou melhor EUA, sendo produzidos 3,93 kg de frutos por $\mathrm{m}^{3}$ de água.
\end{abstract}

Palavras-chave: Capsicum annum, eficiência de uso da água, polímero hidrorretentor.

\section{IRRIGATION LEVELS ASSOCIATED WITH HYDROGEL DOSES IN SWEET PEPPER CROP}

\begin{abstract}
The aim of this paper was to evaluate the development and production of sweet pepper plants, Nathalie cultivar, in function of irrigation levels and hydrogel doses. The experiment was carried in a Red Latosol at the Goiano Federal Institute in Morrinhos, Goias, Brazil. The experimental design

\footnotetext{
${ }^{1}$ Doutorando em Agronomia (Solo e Água), Universidade Federal de Goiás, Rodovia Goiânia-Nova Veneza, km 0, s/n, Campus Samambaia, CEP: 74690-900, Goiânia, Goiás, Brasil. E-mail: heliomatos5@ hotmail.com

${ }^{2}$ Dr. Irrigação e Drenagem, Instituto Federal Goiano/Campus Morrinhos, Morrinhos, Goiás, Brasil. E-mail: cesar.antonio@ifgoiano.edu.br

${ }^{3}$ Doutorando em Ciências Agrárias (Agronomia), Instituto Federal Goiano /Campus Rio Verde, Rio Verde, Goiás. Email: alefe_viana@hotmail.com
} 
was a randomized complete block design with four replications, in the $4 \times 5$ split plots scheme, being four irrigation levels $(50 \%, 75 \%, 100 \%$ and $125 \%$ evaporation in class A pan - ECA) and five hydrogel doses $\left(0,125,250,375\right.$ and $\left.500 \mathrm{~mL} \mathrm{hole}^{-1}\right)$. The hydrogel was diluted in water to $2.5 \mathrm{~g} \mathrm{~L}^{-1}$, provided in the transplanting pit. The following parameters were evaluated: plant height and stem diameter at 90 and 120 days after transplant (DAT); fruits number per plant, fruit diameter, fruit $\mathrm{pH}$, fruit production at 100 and 120 DAT; and water use efficiency. The irrigation excess, at a level greater than or equal to $100 \%$ of the ECA, reduced the number of commercial fruits, the production the fruits per plant, the diameter and $\mathrm{pH}$ of the fruit. The hydrogel addition in the soil does not lead to a significant increase in production and quality the sweet pepper fruit. Irrigation at $75 \%$ of the ECA provided the USA better, with $3.93 \mathrm{~kg}$ of fruit produced per $\mathrm{m} 3$ of water

Keywords: Capsicum annum, water use efficiency, hydro-absorbent polymer.

\section{INTRODUÇÃO}

O pimentão (Capsicum annuum L.) está entre as dez principais hortaliças cultivadas no Brasil (ALBUQUERQUE et al., 2012). A produção anual é estimada em 253.807 toneladas, representada principalmente pelos estados de São Paulo (23,7\%), Minas Gerais $(10,4 \%)$ e Goiás $(14,8 \%)$, com plantios próximos a grandes centros distribuidores (IBGE, 2017). A cultura propicia geração de inúmeros empregos diretos e indiretos, sendo crescente a demanda de frutos no mercado. $\mathrm{O}$ fruto verde é o mais comercializado e consumido no Brasil (MAROUELLI; SILVA, 2012), apresentando em sua composição, assim como no fruto maduro, alto teor de vitamina C (DAMATTO JÚNIOR et al., 2010).

A cultura do pimentão apresenta alta demanda evapotranspirométrica durante $\mathrm{o}$ ciclo. A necessidade hídrica depende das variáveis meteorológicas locais, duração do ciclo, cultivar, sistema de irrigação e ambiente de cultivo, se em campo ou em casa de vegetação, variando de $450 \mathrm{~mm}$ a $650 \mathrm{~mm}$ (MAROUELLI; SILVA, 2012). Albuquerque et al. (2012) relatam necessidades hídricas do pimentão variando de 600 a $900 \mathrm{~mm}$, entretanto, conforme Doorenbos e Kassam (1994), pode atingir $1250 \mathrm{~mm}$ para cultivares de ciclo mais longo.

O monitoramento da lâmina de irrigação é fundamental, pois o excesso de água favorece incidência de doenças, e o déficit reduz a produtividade, em decorrência do abortamento de flores, abscisão de frutos e desequilíbrio nutricional, causando podridão apical (SEZEN et al., 2006; CARVALHO et al., 2016). Conforme Sezen et al. (2006), a redução na produtividade é mais acentuada quando o déficit hídrico é aplicado na fase de florescimento até a colheita.

Gadissa e Chemeda (2009) experimentaram três níveis de irrigação $(50 \%$, $75 \%$ e $100 \%$ da ETc) e dois métodos de plantio na cultura do pimentão, em linhas simples, espaçadas em 0,3 x 1,0 m, e linhas duplas, no espaçamento $0,3 \times 0,3 \times 1,0 \mathrm{~m}$. Verificaram que a lâmina equivalente a $100 \%$ da ETc proporcionou maior altura de plantas, produtividade e número de frutos por planta, em comparação aos níveis de 50 e $75 \%$ da ETc.

Visando maximizar a eficiência de uso da água e obter altos rendimentos, a adição de hidrogel ao solo, associada à irrigação, é uma alternativa promissora. Os hidrogéis são polímeros condicionadores de solo, hidrorretentores, geralmente à base de amido ou sintéticos, derivados de petróleo, constituídos de cadeias longas de acrilamidas ou poliacrilato de potássio (WANG; GREGG, 1990). São capazes de reter de 150 a 400 vezes a sua massa em água, aumentando seu volume em até 100 vezes, tornando-se um gel (MARQUES et al., 2013; NAVROSKI et al., 2015), que adicionado ao solo, possibilita maior capacidade real de água e maiores turnos de irrigação em períodos de estiagem.

Além de reduzir a frequência de irrigação, o polímero possibilita menor lixiviação de nutrientes e aumento da CTC capacidade de troca catiônica (AZEVEDO et 
al., 2006; LÓPEZ-ELÍAS et al., 2013). No entanto, deve-se observar parâmetros intrínsecos como a profundidade efetiva do sistema radicular, que varia conforme Marouelli et al. (2008), de 25 a $45 \mathrm{~cm}$ para pimentão nas fases de máximo de desenvolvimento vegetativo, ou extrínsecos como a irrigação total necessária, para melhor gestão da água na cultura (PADRÓN et al. 2015a).

Nesse contexto, níveis adequados da irrigação e a utilização de hidrogel podem proporcionar plantas mais produtivas, com frutos de melhor qualidade. Diante disso, objetivou-se neste trabalho avaliar o desenvolvimento, a produção e a eficiência no uso da água pelo pimentão, em função de níveis de irrigação e doses de hidrogel.

\section{MATERIAL E MÉTODOS}

O experimento foi conduzido em campo, num Latossolo Vermelho Amarelo, de textura argilosa, na área experimental do Instituto Federal Goiano/Campus Morrinhos, Goiás, situada entre as latitudes $17^{\circ} 49^{\prime} 18^{\prime \prime}$ e $17^{\circ} 49^{\prime} 20^{\prime \prime} \mathrm{S}$ e as longitudes $49^{\circ} 12^{\prime} 11^{\prime \prime}$ e 49 12'14'O, com altitude de, aproximadamente, $885 \mathrm{~m}$.

A região apresenta clima tropical, do tipo Aw, segundo a classificação de KöppenGeiger (CARDOSO et al., 2014), caracterizado por uma estação chuvosa, de outubro a abril, e uma estação de estiagem, de maio a setembro, sendo a temperatura média anual entre 23 e $24^{\circ} \mathrm{C}$.

O preparo do solo foi realizado por meio de gradagens, aradora e niveladora. $\mathrm{O}$ plantio foi realizado em 16 de julho de 2016, em campo, utilizando-se mudas da cultivar Nathalie com aproximadamente $12 \mathrm{~cm}$ de altura, produzidas em viveiro comercial.

O espaçamento utilizado foi de $0,30 \mathrm{~m}$ entre plantas e $1,10 \mathrm{~m}$ nas entrelinhas. As adubações foram realizadas conforme recomendações da $5^{\text {a }}$ aproximação para 0 estado de Goiás (CFSG, 1988), e análises químicas de amostra composta, realizadas no
Laboratório Vitassolos, em Goiatuba, GO, sendo a amostra obtida a partir de amostras simples coletadas em ziguezague e homogeneizadas.

No plantio, foram aplicados $50 \mathrm{~kg}$ de $\mathrm{N}$, $400 \mathrm{~kg}$ de $\mathrm{P}_{2} \mathrm{O}_{5}, 60 \mathrm{~kg}$ de $\mathrm{K}_{2} \mathrm{O}, 2 \mathrm{~kg}$ de boro e $4 \mathrm{~kg}$ de zinco ha ${ }^{-1}$. As adubações em cobertura foram de $100 \mathrm{~kg}$ de $\mathrm{N}$ e $100 \mathrm{~kg}$ de $\mathrm{K}_{2} \mathrm{O} \mathrm{ha}{ }^{-1}$, ambos os nutrientes parcelados em doses de $50 \mathrm{~kg} \mathrm{ha-1}$, aos 30 e 60 dias após o transplantio.

Utilizou-se o sistema de irrigação por gotejamento, com emissores autocompensantes de vazão igual a $1,0 \mathrm{~L} \mathrm{~h}^{-1}$, operando na pressão de $100 \mathrm{kPa}$. O sistema foi constituído de conjunto motobomba, cabeçal de controle com filtro de discos e manômetro, tubulação de recalque, linhas de derivação, linhas laterais de polietileno de baixa densidade - PEBD, com emissores in line, espaçados em $0,30 \mathrm{~m}$, sendo um emissor por planta.

O delineamento experimental foi o de blocos casualizados, em esquema de parcelas subdivididas $4 \times 5$ com quatro repetições, sendo quatro níveis de irrigação (50; 75; 100 e $125 \%$ da evaporação em tanque classe A- ECA) nas parcelas, e cinco doses do hidrogel Forth Gel®, do fabricante Tecnutri do Brasil (0; $125 ; 250 ; 375$ e $500 \mathrm{~mL}$ cova $^{-1}$ ) nas subparcelas. O hidrogel foi diluído em água na proporção de 2,5 $\mathrm{g} \mathrm{L}^{-1}$, obtendo-se uma pasta viscosa, a qual foi aplicada nas covas de plantio, nas doses especificadas. Em seguida, adicionou-se uma cobertura de solo, com espessura de aproximadamente $8 \mathrm{~cm}$, separando o polímero, o fertilizante e a muda. A subparcela foi constituída de dezoito plantas, sendo três linhas de seis plantas. As quatro plantas da linha central constituíram a área útil da unidade experimental.

A evapotranspiração da cultura (ETc) foi estimada em função da evapotranspiração de referência (ETopenman-Monteith), obtida a partir de dados meteorológicos registrados em estação da Davis Instruments, próxima ao experimento.

A ETc (Figura 1A) também foi obtida por meio de tanque classe A 
(Equação 1), instalado no centro da área experimental, sobre estrado de madeira, com ausência de vegetação ao seu redor, numa bordadura de $1 \mathrm{~m}$.

$$
\mathrm{ETc}=\mathrm{Kc} \cdot \mathrm{Kp} . \mathrm{ECA}
$$

Em que: Kc é o coeficiente de cultivo (ALLEN et al., 1998); Kp é o coeficiente do tanque classe $\mathrm{A}$, em função da velocidade média do vento e umidade relativa do ar, em área sem bordadura de grama (DOORENBOS; KASSAM, 1994); ECA é a evaporação de água em tanque classe $\mathrm{A}(\mathrm{mm})$.Utilizou-se $\mathrm{Kp}$ igual a 0,7 , conforme recomendação de Doorenbos e Kassam (1994), para velocidade média do vento menor que $2,0 \mathrm{~m} \mathrm{~s}^{-1}$ e umidade relativa do ar entre 40 e $70 \%$ durante o período experimental.

Para obtenção da ETc, foram utilizados os seguintes valores de $\mathrm{Kc}$, propostos por Allen et al. (1998), nas fases fenológicas do pimentão: 0,55 (fase inicial, até 30 dias), 0,80 (floração, de 31 a 60 dias), 1,05 (frutificação, de 61 a 91 dias) e 0,90 (início da colheita, de 91 dias ao final do ciclo).

As irrigações foram realizadas com turno de rega de 2 dias, sendo as leituras no tanque classe A em antecedência às irrigações. Os tempos de irrigação foram obtidos através da Equação 2, considerando a ECA, área molhada e vazão de emissores:

$\mathrm{Ti}=\frac{60 \times(\mathrm{N} \times \mathrm{ECA} \times \mathrm{Am})}{\mathrm{n} \times \mathrm{q}}$

Em que: Ti - tempo de irrigação (min); 60 - ajuste de unidades; $\mathrm{N}$ - nível de irrigação (\% ETc, em decimal); ECA - evaporação no tanque classe A, acumulada entre duas irrigações consecutivas (mm); Am - área da faixa molhada $\left(\mathrm{m}^{2}\right)$ em cada nível de irrigação; $\mathrm{n}$ - número de emissores na área molhada; e $\mathrm{q}$ - vazão dos emissores $\left(\mathrm{L} \mathrm{h}^{-1}\right)$.

O controle de plantas daninhas foi realizado por meio de capinas manuais, com enxada. $O$ controle preventivo de insetospraga se deu através de pulverizações dos inseticidas clorfenapir, acetamiprid, aos 15 e 60 dias, e imidacloprid, aos 90 dias após transplantio, nas dosagens recomendadas pelos fabricantes desses produtos, visando controle de Diabrotica speciosa, Bemisia tabaci, Aphis gossypii e Thrips sp. Visando controle de Cercospora capsici, Colletotrichum gloeosporioides e Xanthomonas vesicatoria, foram aplicados os fungicidas azoxistrobinadifenoconazol no transplantio e aos 30 dias, e oxicloreto de cobre aos 15, 60 e 90 dias, conforme dosagens recomendadas para pimentão. A alternância dos princípios ativos teve como intuito evitar a resistência de insetos e patógenos.

Realizou-se a eliminação de brotações laterais nas plantas, abaixo da primeira bifurcação. Acima desta, quatro hastes foram selecionadas para condução, eliminando-se as demais. O tutoramento foi realizado através de barbantes e estacas de 1,0 m de altura, aos 30 dias após transplantio.

Os tratamentos primários (níveis de irrigação) foram aplicados a partir de 25 dias após o transplantio (DAT). Ao término do experimento, a lâmina total aplicada foi contabilizada, assim como a ocorrência de chuvas na área, onde a soma de chuva e irrigação no nível de $125 \%$ foi $395 \mathrm{~mm}$ superior ao aplicado no nível de $50 \%$ da ECA (Figura 1B). As chuvas foram mal distribuídas, e nos dias em que ela era superior a algum dos níveis de irrigação (\% ECA), a irrigação era realizada de forma parcial, complementar às chuvas. 
(A)

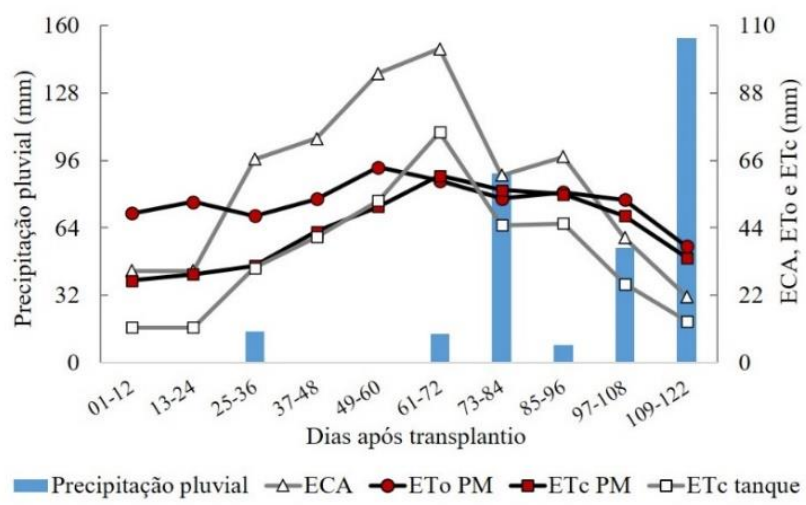

(B)

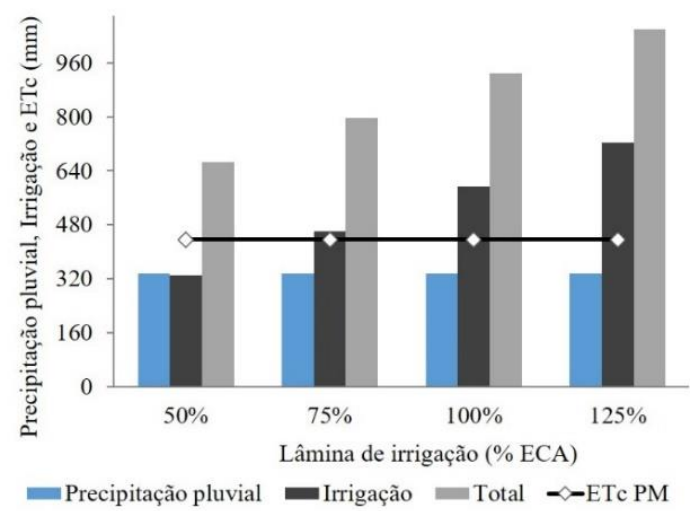

Figura 1. Balanço da precipitação pluvial, evaporação no tanque classe (ECA), evapotranspiração de referência (ETo) e evapotranspiração da cultura (ETc) do pimentão, pelos métodos de Penman-Monteith (PM) e do tanque, no período de 16 de julho a 15 de novembro de 2016 (A) e registro da precipitação, ETc acumulada e irrigação nos tratamentos primários (B). Morrinhos - GO, 2016.

As avaliações foram efetuadas em quatro plantas da área útil, mensurando os seguintes parâmetros: altura de plantas (AP, cm), aos 90 e 120 dias após transplantio (DAT); diâmetro do caule (DC, mm), medido com paquímetro digital, aos 90 e 120 DAT; número de frutos comerciais (NFC) por planta e diâmetro médio do fruto (DF, cm), em duas colheitas, aos 100 e 120 DAT; pH do fruto; produção de frutos comerciais (PFC, g planta ${ }^{-1}$ ); e, eficiência de uso da água de irrigação + chuva (EUA), $\mathrm{em} \mathrm{kg} \mathrm{m}^{-3}$, conforme a equação 3 :

$\mathrm{EUA}=\frac{\mathrm{PFC}}{(\mathrm{I}+\mathrm{P})}$

Em que: I - volume de água de irrigação $\left(\mathrm{m}^{3}\right)$ aplicado na faixa molhada, em cada nível de irrigação; $\mathrm{P}$ - volume de precipitação pluvial na faixa molhada $\left(\mathrm{m}^{3}\right)$; $\mathrm{PFC}-$ produção de frutos comerciais $(\mathrm{kg})$. Os dados obtidos foram submetidos à análise de variância pelo teste $\mathrm{F}(P<0,05)$, utilizando-se o software SISVAR - Sistema para Análises de Variância (FERREIRA, 2011). Os parâmetros significativos, foram analisados através de equações de regressão.

\section{RESULTADOS E DISCUSSÃO}

O resumo das análises de variância (Tabela 1) indica efeito significativo dos níveis de irrigação $(P<0,01)$ na altura de plantas (AP) e no diâmetro de caule (DC), aos 90 dias após transplantio (DAT) das mudas de pimentão, no diâmetro de fruto (DF) aos 120 DAT, na produção de frutos comerciais (PFC) e na eficiência de uso da água (EUA) de irrigação e chuva. Também apresenta significância $(P<0,05)$ na AP aos 120 DAT, no número de frutos comerciais (NFC) aos 100 DAT e NFC total, e no $\mathrm{pH}$ dos frutos.

Verifica-se efeito do polímero hidrogel $(\mathrm{p}<0,05)$ apenas na altura de plantas, aos 90 DAT. Não se observou interação significativa de tratamentos primários e secundários nos parâmetros avaliados, com exceção do $\mathrm{pH}$ do fruto $(P<0,05)$. Aos 90 DAT, a maior altura de planta foi estimada em $34,4 \mathrm{~cm}$, com o nível de irrigação equivalente a $83,3 \%$ da ECA (Figura 2A), enquanto aos 120 DAT foi observada maior altura, de $51,9 \mathrm{~cm}$, com a reposição de $75 \%$ da ECA, não havendo um modelo de equação significativa que se ajusta aos dados. 
Tabela 1. Resumo das análises de variância da altura de plantas (AP, cm), diâmetro de caule (DC, $\mathrm{mm}$ ), número de frutos comerciais ( $\mathrm{NFC}$, frutos planta ${ }^{-1}$ ), diâmetro médio do fruto ( $\left.\mathrm{DF}, \mathrm{cm}\right), \mathrm{pH}$ do fruto (pH-F), produção de frutos comerciais (PFC, g planta ${ }^{-1}$ ) e eficiência de uso da água (EUA, $\mathrm{kg}$ $\mathrm{m}^{-3}$ ) em cultivo de pimentão cv. Nathalie, em função de níveis de irrigação e doses de hidrogel.

\begin{tabular}{ccccccccc}
\hline \multirow{2}{*}{ Parâmetros avaliados } & & \multicolumn{5}{c}{ Fonte de variação } & & $\mathrm{CV}_{\text {Irrigação }}$ \\
& DAT & $\begin{array}{c}\text { Irrigação } \\
(\mathrm{I})\end{array}$ & $\begin{array}{c}\text { Hidrogel } \\
(\mathrm{H})\end{array}$ & $\begin{array}{c}\text { I x H } \\
\text { CV }\end{array}$ & Bloco & $\begin{array}{c}\text { Hidrogel } \\
(\%)\end{array}$ & $\begin{array}{c}\text { Média } \\
\text { geral }\end{array}$ \\
\hline \multirow{2}{*}{ AP } & 90 & $13,85^{* *}$ & $3,19^{*}$ & $1,15^{\text {ns }}$ & $6,19^{*}$ & 20,27 & 13,76 & 30,34 \\
& 120 & $4,56^{*}$ & $2,12^{\text {ns }}$ & $1,34^{\text {ns }}$ & $3,23^{\text {ns }}$ & 14,74 & 10,96 & 47,04 \\
DC & 90 & $25,29^{* *}$ & $1,70^{\text {ns }}$ & $0,18^{\text {ns }}$ & $24,11^{* *}$ & 9,17 & 11,52 & 6,11 \\
& 120 & $0,65^{\text {ns }}$ & $1,12^{\text {ns }}$ & $0,54^{\text {ns }}$ & $2,97^{\text {ns }}$ & 15,32 & 10,31 & 10,84 \\
\hline & 100 & $4,40^{*}$ & $0,54^{\text {ns }}$ & $0,93^{\text {ns }}$ & $5,72^{*}$ & 53,19 & 41,71 & 1,51 \\
NFC & 120 & $3,67^{\text {ns }}$ & $1,02^{\text {ns }}$ & $1,18^{\text {ns }}$ & $8,76^{* *}$ & 49,43 & 47,51 & 3,33 \\
& Total & $5,18^{*}$ & $1,02^{\text {ns }}$ & $1,13^{\text {ns }}$ & $10,51^{* *}$ & 43,11 & 39,63 & 4,84 \\
\hline \multirow{2}{*}{ DF } & 100 & $2,51^{\text {ns }}$ & $0,48^{\text {ns }}$ & $0,58^{\text {ns }}$ & $0,47^{\text {ns }}$ & 16,22 & 13,39 & 4,07 \\
& 120 & $12,63^{* *}$ & $0,49^{\text {ns }}$ & $0,85^{\text {ns }}$ & $0,64^{\text {ns }}$ & 13,79 & 15,77 & 3,74 \\
\hline pH-F & Média: & $4,08^{*}$ & $2,16^{\text {ns }}$ & $2,03^{*}$ & $5,02^{*}$ & 2,93 & 2,91 & 5,87 \\
PFC & Total: & $7,80^{* *}$ & $1,16^{\text {ns }}$ & $0,93^{\text {ns }}$ & $15,28^{* *}$ & 43,21 & 41,93 & 268,06 \\
EUA & Total: & $12,66^{* *}$ & $1,05^{\text {ns }}$ & $0,83^{\text {ns }}$ & $14,06^{* *}$ & 44,89 & 42,86 & 2,69 \\
\hline
\end{tabular}

**Significativo a $1 \%$ pelo teste $\mathrm{F}$; * Significativo a $5 \%$ pelo teste $\mathrm{F}$; ${ }^{\text {ns }}$ - Não significativo pelo teste $\mathrm{F}$
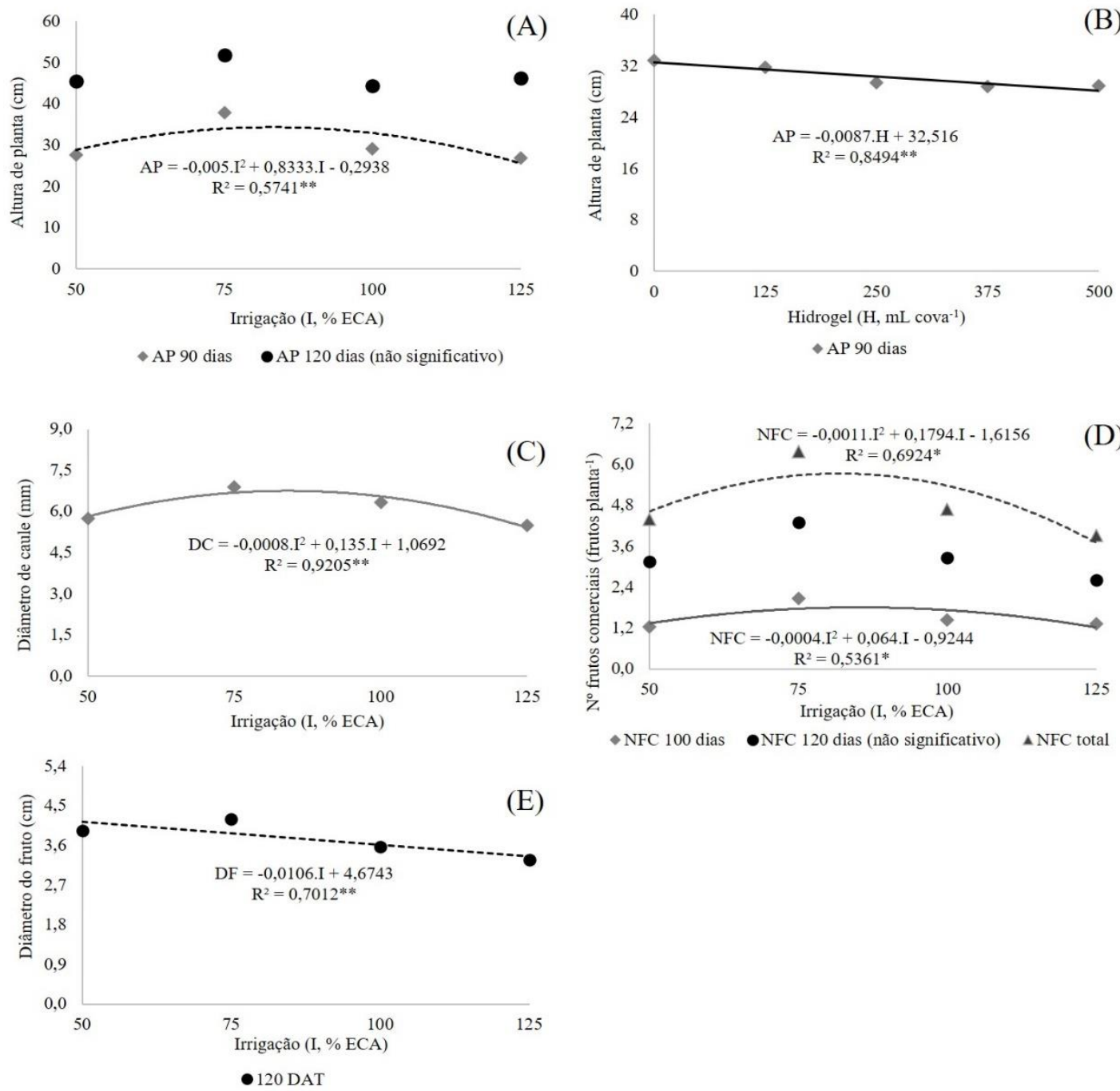

Figura 2. Altura de planta (A e B), diâmetro de caule (C), número de frutos comerciais (D) e diâmetro do fruto (E) de pimentão cv. Nathalie, em função de níveis de irrigação e doses de hidrogel. 
Os níveis de irrigação de 100 e $125 \%$ da ECA, equivalentes a 593,3 e 724,6 mm durante o ciclo, ocasionaram redução na altura de plantas, o que indica excesso de água, pois foi superior à evapotranspiração da cultura (ETcPenman-Monteith) acumulada, de 435,4 mm, obtida em função do kc nas fases fenológicas do pimentão, conforme Allen et al. (1998). Dentre as consequências da irrigação nos maiores níveis somada ao excesso de chuvas na fase final do experimento, tem-se a lixiviação de nutrientes, como o nitrogênio, que possivelmente influenciou na altura de planta. Resultados condizentes foram obtidos por Padrón et al. (2015a), em pesquisa sobre lâminas e frequências de irrigação em pimentão, ao constatarem menor altura de plantas, de $72,4 \mathrm{~cm}$, no nível de irrigação de $100 \%$ da ETc, e maior altura, de $91,5 \mathrm{~cm}$, no nível de $60 \%$ da ETc, utilizando irrigação diária.

A adição de doses crescentes de hidrogel na cova de transplantio proporcionou redução linear da AP aos 90 DAT (Figura 2B), podendo essa redução ter sido influenciada por maior retenção de água no solo com hidrogel e, consequentemente, à menor absorção de nutrientes em camadas mais profundas do solo. Entretanto, a utilização do polímero em outras olerícolas, como a abóbora, propiciou efeito contrário, conforme Azambuja et al. (2015), sendo maior a altura das plantas nas maiores doses.

O diâmetro do caule, aos 90 DAT (Figura 2C) apresentou valor máximo estimado em $6,76 \mathrm{~mm}$, com o nível de irrigação de $84,37 \%$ da ECA. A partir deste nível apresentou incrementos decrescentes, reduzindo o DC a $5,48 \mathrm{~mm}$, no nível de $125 \%$ da ECA.

Padrón et al. (2015a) avaliaram DC, experimentando frequências e lâminas de irrigação no pimentão híbrido Tirano, entretanto, não constataram diferença significativa entre tratamentos. Por outro lado, Santana et al. (2004) aplicaram tensões de água no solo $(10,30,50$ e $60 \mathrm{kPa})$ em cultivo de pimentão, e constataram que o DC foi maior nas plantas irrigadas a um menor potencial mátrico.

$\mathrm{O}$ número de frutos comerciais (NFC) apresentou valor máximo de 1,63 frutos planta $^{-1}$, na colheita aos 100 DAT, estimado com nível ótimo de irrigação de $80 \%$ da ECA. Considerando as duas colheitas, a reposição de $81,5 \%$ da ECA proporcionou maior NFC, totalizando 5,7 frutos planta ${ }^{-1}$ (Figura 2D).

O diâmetro do fruto, aos 120 DAT (Figura 2E) foi inversamente proporcional aos níveis de irrigação, apresentando decréscimo linear à medida que aumentou a reposição de água, de 50 a $125 \%$ da ECA. Por outro lado, Furlan et al. (2002), experimentando lâminas de irrigação $(60,80,100$ e $120 \%$ da evaporação em tanque classe A) e adição de $\mathrm{CO}_{2}$ em pimentão cv. Mayata, não constataram efeito significativo das lâminas no diâmetro do fruto, obtendo diâmetros de 6,52 a 7,69 cm. Aragão et al. (2012), avaliando níveis de irrigação iguais a 50,75, 100 e $125 \%$ da evaporação em tanque classe $\mathrm{A}$, e doses de $\mathrm{N}$ em pimentão cv. Magali, verificaram aumento do diâmetro de fruto, de 38 a $40 \mathrm{~mm}$, elevando o nível de irrigação de 75 a $100 \%$ da ECA, com adição de $75 \%$ da dose de nitrogênio recomendada para pimentão. Esses valores são superiores ao encontrado neste trabalho, uma vez ter obtido frutos de $3,6 \mathrm{~cm}$ de diâmetro na irrigação a $100 \%$ da ECA, podendo esse resultado ser atribuído ao excesso hídrico de chuva + irrigação, superando a ETc.

Padrón et al. (2015a) constataram que o diâmetro do fruto não diferiu com a aplicação de lâminas iguais a 60, 80 e 100\% da ETc calculada a partir da evaporação em tanque classe A. Koetz et al. (2010), em estudo sobre a caracterização agronômica de frutos de tomateiro industrial, sob irrigação por gotejamento no sudoeste de Goiás, observaram que a reposição até $125 \%$ da irrigação total necessária para atingir a condição de capacidade de campo, propiciou aumento no diâmetro e na massa dos frutos.

$\mathrm{O}$ valor médio de diâmetro de fruto, de $3,74 \mathrm{~cm}$, na segunda colheita, é relativamente inferior ao da primeira colheita e aos 
diâmetros encontrados por Furlan et al. (2002) e Araújo et al. (2009), provavelmente por terem sido colhidos todos os pimentões das
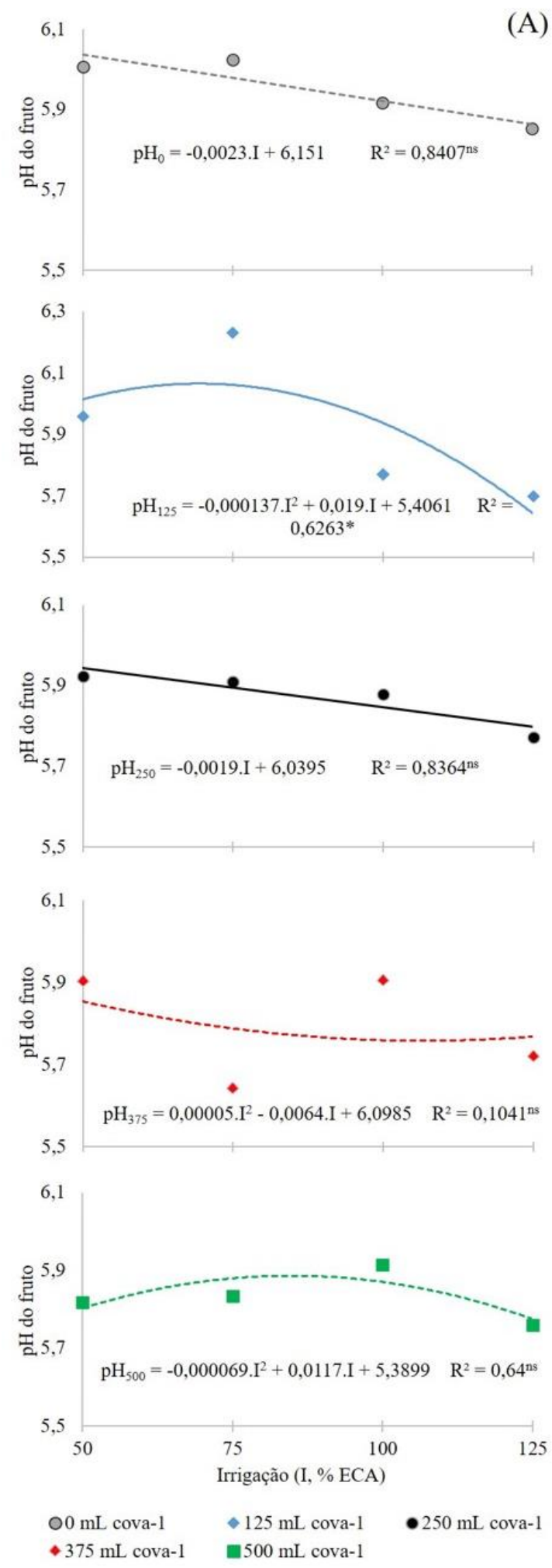

Figura 3. Potencial hidrogeniônico $(\mathrm{pH})$ de frutos de pimentão cv. Nathalie, em função de níveis de irrigação dentro de cada dose de hidrogel (A) e vice-versa (B). plantas úteis para avaliação do diâmetro de fruto, não deixando frutos pequenos em fase de crescimento para posterior colheita.
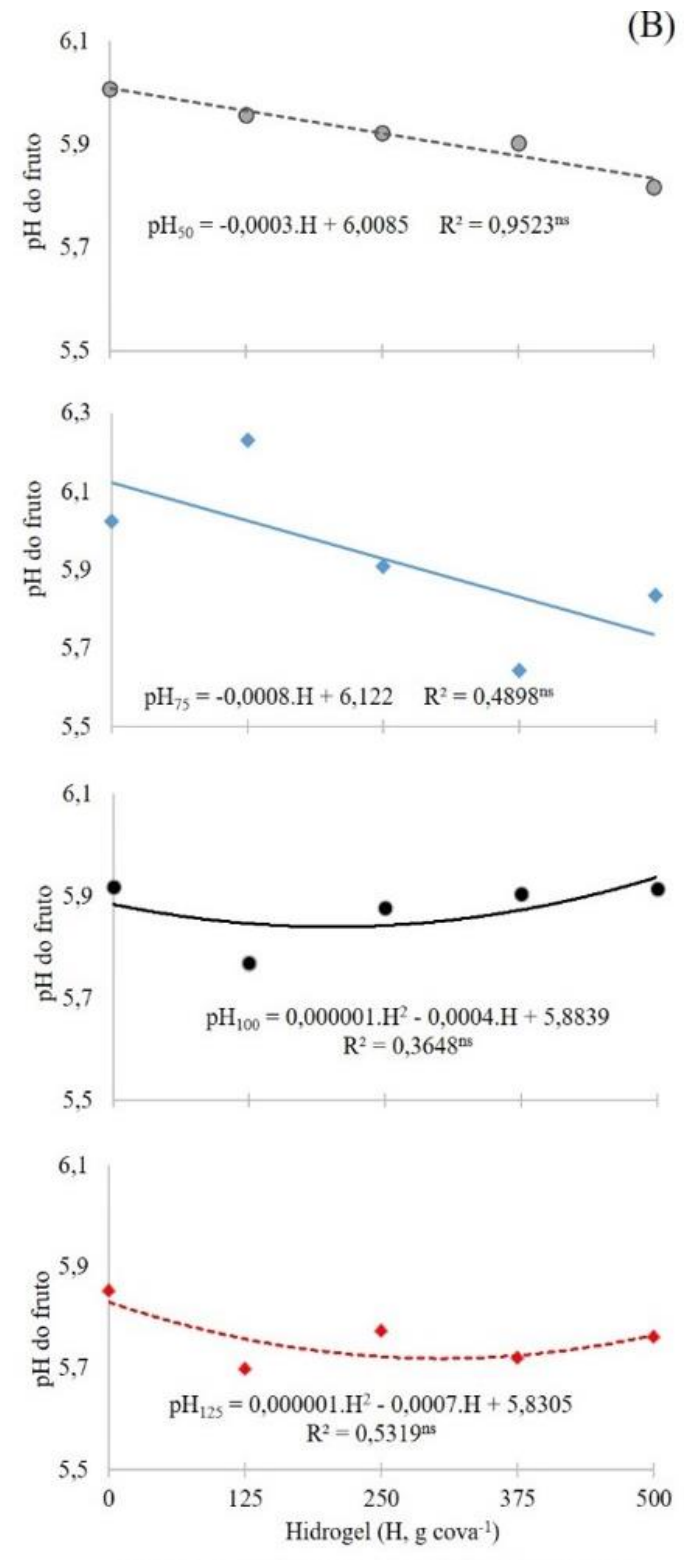

$050 \% \mathrm{ECA} \bullet 75 \% \mathrm{ECA} \bullet 100 \% \mathrm{ECA} \bullet 125 \% \mathrm{ECA}$

B)

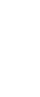

\section{.}

\section{.}




\section{NÍVEIS DE IRRIGAÇÃO ASSOCIADOS A DOSES DE HIDROGEL NA CULTURA DO PIMENTÃO}

Apesar da interação significativa dos níveis de irrigação e doses de hidrogel no $\mathrm{pH}$ do fruto, em todas as doses houve tendência de redução do $\mathrm{pH}$ do fruto nos maiores níveis de irrigação (Figura 3A).

Dentre os modelos de equação analisados, apenas na dose de $125 \mathrm{~g} \mathrm{cova}^{-1}$, de hidrogel, houve significância $(\mathrm{p}<0,05)$ para $\mathrm{o}$ modelo quadrático, sendo observado e estimado nos níveis de $75 \%$ e $69,3 \%$ da ECA, pH máximo de 6,23 e 6,06, respectivamente.

Valores estes acima dos obtidos por Damatto Júnior et al. (2010), de 5,05 a 5,41. Com relação ao desdobramento das doses de hidrogel em cada nível de irrigação (Figura 3B), houve tendência houve tendência de menor $\mathrm{pH}$ do fruto nas doses de 375 e $500 \mathrm{~mL}$ $\operatorname{cova}^{-1}$ e maior $\mathrm{pH}$ na ausência de hidrogel, sobretudo no nível de $50 \%$ da ECA, dando indícios que à medida que diminui a retenção de água na cova de transplantio, eleva-se o $\mathrm{pH}$ do fruto colhido verde.

Ao contrário do observado neste trabalho, Medeiros et al. (2012) constataram maior $\mathrm{pH}$ do fruto à medida que aumentou a lâmina de irrigação. As variações de $\mathrm{pH}$ do fruto se devem sobretudo à cultivar de pimentão e ao estádio de formação/maturação do fruto, no momento da colheita, que

(A)

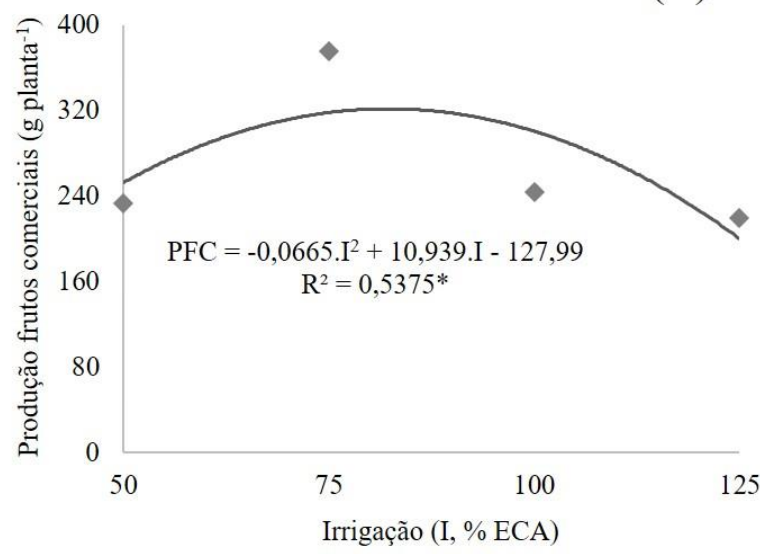

depende do nível de irrigação, onde a maturação fisiológica é mais rápida nas plantas submetidas ao déficit hídrico.

Damatto Júnior et al. (2010) obtiveram maiores valores de $\mathrm{pH}(5,41)$ em frutos verdes, em comparação a frutos $50 \%$ maduros $(\mathrm{pH}=$ 5,09), parâmetro este que segundo Cochran (1964), tende a aumentar em frutos verdes, atingindo valor máximo de 6,52 , enquanto os frutos com maturação fisiológica adiantada, apresentam maior teor de vitamina $\mathrm{C}$ (ácido ascórbico).

Dessa forma, o estádio de maturação do fruto e o regime de irrigação são fundamentais na definição do momento de colheita, assim como na valorização do fruto no mercado. Considerando as duas colheitas, o nível de irrigação que propiciou maior produção de frutos comerciais (PFC) foi de 82,2\% da ECA, sendo estimada uma PFC de 321,9 g planta $^{-1}$. (Figura 4A).

À medida em que se aumenta o nível de irrigação, os incrementos de produção são decrescentes, sendo necessários volumes de água de 363,4; 477,9; 592,3 e 706,8 L de água por quilograma de frutos, nos níveis de $50,75,100$ e $125 \%$ da ECA, respectivamente.

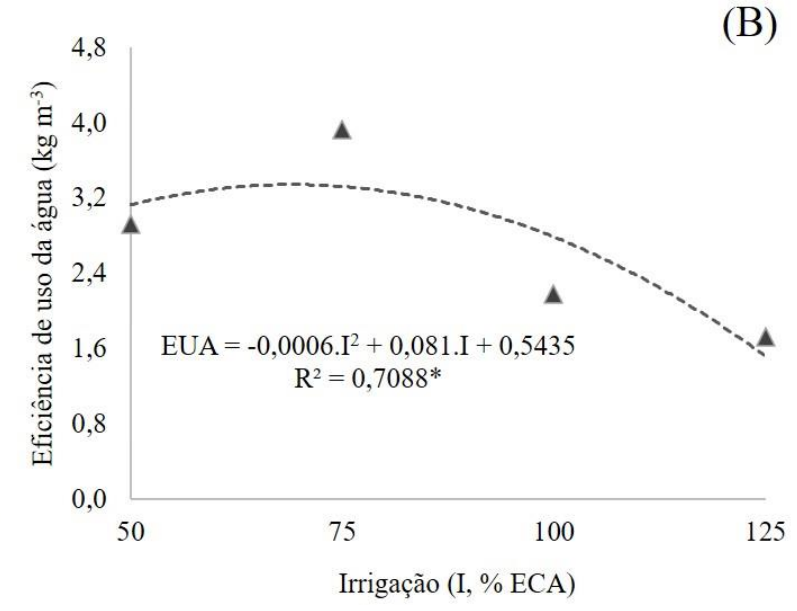

Figura 4. Produção de frutos comerciais (A) e eficiência de uso da água de chuva + irrigação (B) na produção de pimentão cv. Nathalie, em função de níveis de irrigação (I).

A eficiência de uso da água (EUA) apresentou resposta quadrática com o aumento dos níveis de irrigação (Figura 4B), sendo produzidos $3,93 \mathrm{~kg} \mathrm{~m}^{3}$ de água, na irrigação a
$75 \%$ da ECA + chuva. Considerando apenas a chuva acumulada $(335,4 \mathrm{~mm})$ durante o período experimental, estima-se que seriam produzidos $0,543 \mathrm{~kg}$ de frutos, por $\mathrm{m}^{3}$ de água. 
O volume total de água fornecido por planta, na faixa molhada, variou de 79,8 a 127,2 L, nos níveis de 50 e $125 \%$ da ECA, respectivamente, sendo que desses volumes, 40,2 L foram de água da chuva. Conforme Castro Júnior et al. (2015), na definição do nível ótimo de irrigação deve-se considerar além da produção máxima de frutos comerciais, os custos da água e de energia requerida no bombeamento, o custo do equipamento de irrigação, as receitas advindas da comercialização do pimentão, além de outros custos, que compõem a cadeia produtiva da cultura, sendo necessário determinar indicadores de viabilidade econômica do investimento, considerando a EUA.

Maior reposição de água não significa maior produtividade, uma vez que o excesso de água, por irrigação e chuva imediatamente após a irrigação, ocasiona lixiviação de nutrientes, como nitrogênio e potássio. Resultado similar foi encontrado por Padrón et al. (2015a), na sexta colheita do pimentão, sendo a lâmina de $80 \%$ ETc, com frequência a cada dois dias, a de maior produção, seguida da lâmina de $60 \%$ ETc, com frequência de irrigação diária, tendo a lâmina de $100 \%$ apresentado menor produção.

Com relação à eficiência de uso da água, os resultados são condizentes aos obtidos por Souza et al. (2019), ao verificarem melhor aproveitamento da água no nível de irrigação de 160,45 mm (60\% ETc), em comparação à lâmina de 320,9 mm (120\% ETc). Padrón et al. (2015b) também observaram um declínio na eficiência do uso da água com um aumento nos níveis de irrigação.Aragão et al. (2012) obteve maior eficiência de uso da água de $21,36 \mathrm{~kg} \mathrm{~mm}^{-1} \mathrm{ha}^{-1}$, fazendo reposição de $50 \%$ da ECA. Essa eficiência equivale a $2,136 \mathrm{~kg}$ $\mathrm{m}^{-3}$ de água, sendo superior à obtida neste trabalho.

Por outro lado, Aladenola e Madramootoo (2014) registraram maiores valores de eficiência de uso da água em pimentões irrigados a $120 \%$ e $100 \%$ da ETc. Estes valores indicam que os percentuais de evaporação no tanque superestimam a lâmina de irrigação (mm), quando comparados com os mesmos percentuais da ETc.

\section{CONCLUSÕES}

Níveis de irrigação maior ou igual a $100 \%$ da ECA ocasionam a redução do número de frutos comerciais, da produção de frutos, do diâmetro do fruto e do $\mathrm{pH}$ do fruto;

Nas condições edafoclimáticas onde está pesquisa foi conduzida, em solo argiloso, a adição de hidrogel não propicia ganhos de produção e qualidade de frutos de pimentão;

A melhor eficiência do uso da água foi obtida no nível de $75 \%$ da ECA, com produção de $3,93 \mathrm{~kg} \mathrm{~m}^{-3}$ de água.

\section{REFERÊNCIAS BIBLIOGRÁFICAS}

ALADENOLA, O.; MADRAMOOTOO, C. Response of greenhouse-grown bell pepper (Capsicum annuum L.) to variable irrigation. Canadian Journal of Plant Science, v. 94, n. 2, p. 303-310, 2014. DOI: https://doi.org/10.4141/cjps2013-048

ALBUQUERQUE, F. da S.; SILVA, Ê. F. de F; ALBUQUERQUE FILHO, J. A. C. de; LIMA, G. S. Necessidade hídrica e coeficiente de cultivo do pimentão fertirrigado. Irriga, v. 17, n. 4, p. 481-493, 2012. DOI: https://doi.org/10.15809/irriga.2012v17n4p48 1

ALLEN, R. G.; PEREIRA, L. S.; RAES D; SMITH M. Crop evapotranspiration. Guidelines for computing crop water requirements. Rome: FAO, 1998. 300 p.

ARAGÃO, V. F.; FERNANDES, P. D.; GOMES FILHO, R. R.; CARVALHO, C. M. de; FEITOSA, H. de O.; FEITOSA, E. de O. Produção e eficiência no uso de água do pimentão submetido a diferentes lâminas de irrigação e níveis de nitrogênio. Revista Brasileira de Agricultura Irrigada, v. 6, n. 3, p. 207-216, 2012. DOI: 10.7127/rbai.v6n300086 
ARAÚJO, J. S.; ANDRADE, A. P. de; RAMALHO, C. I.; AZEVEDO, C. A. V. de. Características de frutos de pimentão cultivado em ambiente protegido sob doses de nitrogênio via fertirrigação. Revista Brasileira de Engenharia Agrícola e Ambiental, v. 13, n. 2, p. 152-157, 2009. DOI: $\quad$ https://doi.org/10.1590/S141543662009000200007

AZAMBUJA, L. O.; BENETT, C. G. S.; BENETT, K. S. S.; COSTA, E. Produtividade da abobrinha 'Caserta' em função do nitrogênio e gel hidrorretentor. Revista Científica de Ciências Agrárias, v. 43, n. 4, p. 353-358, 2015. DOI: http://dx.doi.org/10.15361/1984-

5529.2015v43n4p353-358

AZEVEDO, T. L. de F. BERTONHA, A.; FREITAS, P. S. L. de; REZENDE, R.; DALLACORT, R.; BERTONHA, L. C. Retenção de soluções de sulfatos por hidrogel de policrilamida. Acta Scientiarum Agronomy, v. 28, n. 2, p. 287-290, 2006. DOI: https://doi.org/10.4025/actasciagron.v28i2.113 1

CARDOSO, M. R. D.; MARCUZZO, F. F. N.; BARROS, J. R. Classificação climática de Köppen-Geiger para o estado de Goiás e o Distrito Federal. Acta Geográfica, v. 8, n. 16, p. 40-55, 2014. $\quad$ DOI: 10.5654/actageo2014.0004.0016

CARVALHO, J. de A.; REZENDE, F. C.; OLIVEIRA, E. C.; AQUINO, R. F. Pimentão cultivado em ambiente protegido sob diferentes tensões de água no solo. Revista Engenharia na Agricultura, v. 3, n. 3, p. 236-245, 2016.2 DOI: https://doi.org/10.13083/reveng.v24i3.670

CASTRO JÚNIOR, W. L.; OLIVEIRA, R. A. de; SILVEIRA, S. de F. R.; ANDRADE JÚNIOR, A. S. de. Viabilidade econômica de tecnologias de manejo da irrigação na produção do feijão-caupi, na região dos
Cocais-MA. Engenharia Agrícola, v. 35, n. 3, p. 406-418, 2015. DOI: https://doi.org/10.1590/1809-4430-

Eng.Agric.v35n3p406-418/2015

CFSG - Comissão de Fertilidade de Solos de Goiás. Recomendações de corretivos e fertilizantes para Goiás $-\mathbf{5}^{\mathbf{a}}$ aproximação. Goiânia: UFG/ENGOPA, 1988. 101 p. (Informativo Técnico 1).

COCHRAN, H. L. Changes in $\mathrm{pH}$ of the pimiento during maturation. Proceedings of the American Society for Horticultural Science, v. 84, p. 409-41170-72, 1964. DOI:

DAMATTO JUNIOR, E. R.; GOTO, R.; RODRIGUES, D. S.; VICENTINI, N. M.; CAMPOS, A. J. de. Qualidade de pimentões amarelos colhidos em dois estádios de maturação. Revista Científica Eletrônica de Agronomia, v. 17, n. 1, p. 23-30, 2010. DOI: http://www.faef.revista.inf.br/imagens_arquiv os/arquivos_destaque/8S5sEyRKVMtUmUo_ 2013-5-10-16-14-33.pdf

DOORENBOS, J.; KASSAM, A. H. Efeito da água no rendimento das culturas. Campina Grande: UFPB, 1994. 306 p.

FERREIRA, D.F. Sisvar: a computer statistical analysis system. Ciência e Agrotecnologia, v. 35, n. 6, p. 1039-1042, 2011. DOI: https://doi.org/10.1590/S141370542011000600001

FURLAN, R. A.; REZENDE, F. C.; ALVES, D. R. B.; FOLEGATTI, M. V. Lâmina de irrigação e aplicação de $\mathrm{CO}_{2}$ na produção de pimentão cv. Mayata, em ambiente protegido. Horticultura Brasileira, v. 20, n. 4, p.547550, 2002. DOI: https://doi.org/10.1590/S010205362002000400007

GADISSA, T.; CHEMEDA, D. Effects of drip irrigation levels and planting methods in yield and yields components of green pepper (Capsicum annuum L.) in Baku, Ethiopia. 
Agricultural Water Management, v. 96, n. 7, p. 1173-1178, 2009. DOI: https://doi.org/10.1016/j.agwat.2009.07.004

IBGE - Instituto Brasileiro de Geografia e Estatística. Censo agropecuário 2017: resultados preliminares. SIDRA: 2017. Disponível em: <https://sidra.ibge.gov.br/tabela/6619>.

Acesso em: 22 maio 2019.

KOETZ, M.; MASCA, M. G. C. C.; CARNEIRO, L. C.; RAGAGNIN, V. A.; SENA JÚNIOR, D. G. de; GOMES FILHO, R. R. Caracterização agronômica e Brix em frutos de tomate industrial sob irrigação por gotejamento no sudoeste de Goiás. Revista Brasileira de Agricultura Irrigada, v. 4, n. 1, p. 14-22, 2010. DOI: 10.7127/rbai.v4n100022

LÓPEZ-ELÍAS，J.; HUEZ-LÓPEZ， M. A.; RUEDA-PUENTE, E. O.; JIMÉNEZ-LEÓN, J.; RODRÍGUEZ, J. C.; ROMEROESPINOZA, L. K.; DÁVILA-CARRERA, F.X. Evaluación de un polímero hidrófilo en chile anaheim (Capsicum annuum L.) cultivado en invernadero. Terra Latinoamericana, v. 31, n. 2, p. 115-118, 2013.

DOI:

http://www.scielo.org.mx/pdf/tl/v31n2/2395-

8030-tl-31-02-00115.pdf

MAROUELLI, W. A.; SILVA, W. L. C. Irrigação na cultura do pimentão. Circular Técnica 101. Brasília, DF: MAPA, 2012. 20 p.

MAROUELLI, W. A.; SILVA, W. L. de C.; SILVA, H. R . Irrigação por aspersão em hortaliças: qualidade d a água, aspectos do sistema e método prático de manejo. 2 ed., Brasília: Embrapa Informação Tecnológica / Embrapa Hortaliças, $2008 \quad .150$ p. Disponível em:

$<$ http://ainfo.cnptia.embrapa.br/digital/bitstrea m/item/107361/1/CNPH-IRRIG.-POR-

ASPER.-EM-HORT.-08.pdf>. Acesso em: 10 maio 2019.
MARQUES, P. A. A.; CRIPA, M. A. M.; MARTINEZ, E.H. Hidrogel como substituto da irrigação complementar em viveiro telado de mudas de cafeeiro. Ciência Rural, v. 43, n. 1, p.1-7, 2013. https://doi.org/10.1590/S010384782012005000129

MEDEIROS, J. F. de; AROUCHA, E. M. M; DUTRA, I.; CHAVES, S. W. P.; SOUZA, M. S. Efeito da lâmina de irrigação na conservação pós-colheita de melão pele de sapo. Horticultura Brasileira, v. 30, n. 3, p. 514-519, 2012.2 DOI: https://doi.org/10.1590/S010205362012000300026

NAVROSKI, M. C.; ARAÚJO, M. M.; REININGER, L. R. S.; MUNIZ, M. F. B.; PEREIRA, M. de O. Influência do hidrogel no crescimento e no teor de nutrientes nas mudas de Eucalyptus dunnii. Floresta, Curitiba, v. 45, n. 2, p. 315-328, 2015. DOI: http://dx.doi.org/10.5380/rf.v45i2.34411

PADRÓN, R. A. R; GUEDES, J. V. C.; SWAROWSKY, A.; NOGUEIRA, C. U.; CERQUERA, R. R.; DÍAZ-PEREZ, J. C. Supplemental irrigation levels in bell pepper under shade mesh and in open-field: crop coefficient, yield, fruit quality and water productivity. African Journal of Agricultural Research, v. 10, n. 44, p. 41174125 $2015 b$.

DOI:

https://doi.org/10.5897/AJAR2015.10341

PADRÓN, R. A. R.; RAMÍREZ, L. R.; CERQUERA, R.R.; NOGUEIRA, H.M.C. de M.; MUJICA, J.L.U. Desenvolvimento vegetativo de pimentão cultivado com lâminas e frequências de irrigação. Tecnologia \& Ciência Agropecuária, v. 9, n. 2, p. 49-55, 2015a. DOI: https://zeoserver.pb.gov.br/gestaounificada/gu/ emepa/publicacoes/revista-tcaemepa/edicoes/volume-09-2015/volume-9numero-2-abril-2015/tca9209.pdf

SANTANA, M. J. de; CARVALHO, J. de A.; FAQUIN, V.; QUEIROZ, T. M. de. Produção 
do pimentão (Capsicum annuum L.) irrigado sob diferentes tensões de água no solo e doses de cálcio. Ciência e Agrotecnologia, v. 28, n. 6, p. 1385-1391, 2004. DOI: https://doi.org/10.1590/S141370542004000600022

SEZEN, M. S.; YAZAR, A.; EKER, S. Effect of drip irrigation regimes on yield and quality of field grown bell pepper. Agricultural Water Management, v. 81 , n. 1-2, p. 115131 , 2006.

DOI: https://doi.org/10.1016/j.agwat.2005.04.002

SOUZA, Á. H. C. de; REZENDE, R.;
LORENZONI, M. Z.; SANTOS, F. A. S.; OLIVEIRA, J. M. de. Response of bell pepper to water replacement levels and irrigation times. Pesquisa Agropecuária Tropical, v. 49, e53662, p. 1-7, 2019. DOI: https://doi.org/10.1590/198340632019v4953662

WANG, Y. T.; GREGG, L. L. Hydrophilic polymers: their response to amendments and effect on properties of a soilless potting mix. Journal of American Society for Horticultural Science, v. 115, n. 6, p. 943948, 1990.

DOI: https://doi.org/10.21273/JASHS.115.6.943 